\title{
Novel Approaches for Fungal Transcriptomics from Host Samples
}

\author{
Sara Amorim-Vaz and Dominique Sanglard * \\ Institute of Microbiology, University Hospital Center, University of Lausanne, Lausanne, Switzerland
}

Candida albicans adaptation to the host requires a profound reprogramming of the fungal transcriptome as compared to in vitro laboratory conditions. A detailed knowledge of the $C$. albicans transcriptome during the infection process is necessary in order to understand which of the fungal genes are important for host adaptation. Such genes could be thought of as potential targets for antifungal therapy. The acquisition of the C. albicans transcriptome is, however, technically challenging due to the low proportion of fungal RNA in host tissues. Two emerging technologies were used recently to circumvent this problem. One consists of the detection of low abundance fungal RNA using capture and reporter gene probes which is followed by emission and quantification of resulting fluorescent signals (nanoString). The other is based first on the capture of fungal RNA by short biotinylated oligonucleotide baits covering the C. albicans ORFome permitting fungal RNA purification. Next, the enriched fungal RNA is amplified and subjected to RNA sequencing (RNA-seq). Here we detail these two transcriptome approaches and discuss their advantages and limitations and future perspectives in microbial transcriptomics from host material.

Gustavo Henrique Goldman Universidade de Sao Paulo, Brazil

Reviewed by:

Attila Gacser,

University of Szeged, Hungary Sven Krappmann, Friedrich-Alexander-Universität Erlangen-Nürnberg, University

Hospital Erlangen, Germany

*Correspondence:

Dominique Sanglard dominique.sanglard@chuv.ch

Specialty section: This article was submitted to Fungi and Their Interactions, a section of the journal

Frontiers in Microbiology

Received: 22 October 2015 Accepted: 28 December 2015

Published: 19 January 2016

Citation:

Amorim-Vaz S and Sanglard D (2016)

Novel Approaches for Fungal

Transcriptomics from Host Samples.

Front. Microbiol. 6:1571.

doi: 10.3389/fmicb.2015.01571

\section{INTRODUCTION}

Fungal pathogens of mammals are able to live and proliferate in a wide range of host body sites including skin surfaces and mucosa, but also internal organs. In order to successfully colonize or infect tissues offering such different conditions, pathogenic fungi need effective adaptation mechanisms. Adaptive processes are controlled by transcriptional programs and their understanding can provide critical clues in fungal pathogenesis (Odds, 1988; Pfaller and Diekema, 2010).

Fungal transcriptomics in the host has already been addressed in different studies in several pathogens including Cryptococcus neoformans and Aspergillus fumigatus (McDonagh et al., 2008; Chen et al., 2014). These two fungal species are important pathogens causing high mortality in immune-compromised patients (Brown et al., 2012). These studies used microarrays and RNA sequencing (RNA-seq) approaches. In C. neoformans, the transcriptome in the host was performed from cerebrospinal fluid (CSF) from two AIDS patients with cryptococcal meningitis prior to antifungal therapy. The RNA was extracted from fungal cells obtained after CSF centrifugation that corresponded to $10^{6}-10^{8}$ cells. Due to this enrichment step, the RNA extraction yielded almost only fungal material which could be further processed for direct RNA-seq analysis. The authors could analyze the profile of about $97 \%$ of all C. neoformans genes (from a total of about 6800 genes). Some genes were identified as significantly upregulated in vivo as compared to in vitro conditions and were genes previously recognized as contributing to pathogenicity. For example, genes with 
known stress response functions, such as RIM101 (a $\mathrm{pH}$ dependent regulator), ENA1 (an ATPase transporter gene) and CFO1 (a ferroxidase) as well as several transporters were upregulated in host samples (Chen et al., 2014). In A. fumigatus, the transcriptome in the host was approached using experimental nasal instillation to result in pulmonary infection in mice (McDonagh et al., 2008; Bertuzzi et al., 2014). A. fumigatus cells were recovered and enriched from bronchoalveolar lavage (BAL) samples from which RNA was directly extracted. Microarray hybridizations were carried out after amplification of A. fumigatus RNA. This approach allowed the resolution of $95 \%$ of the A. fumigatus genes (from a total of about 9000 genes; McDonagh et al., 2008). The in vivo transcriptional approaches with $A$. fumigatus allowed to perceive iron limitation, alkaline stress and nutrient adaptation as important hostdependent stresses during early stage A. fumigatus infection. They also revealed a biased distribution of host-response genes in subtelomeric regions of chromosomes (McDonagh et al., 2008; Bertuzzi et al., 2014). In a review published by Cairns et al. (2010), C. neoformans and A. fumigatus data were compared with each other to conclude about a high degree of convergence between the in vivo transcriptional data from the two pathogens. Even though the in vivo conditions were quite different between the two experimental systems, carbon metabolism was remarkably shifted to the glyoxylate cycle in the two fungal pathogens (Cairns et al., 2010).

One of the most common fungal pathogens is Candida albicans, which can cause systemic infections in immunocompromised patients with mortality rates of around 50\% (Odds, 1988; Pfaller and Diekema, 2010), and it is a great example of a microorganism with remarkable adaptation capabilities. Some studies have attempted to characterize the transcriptional response of $C$. albicans during the infection process. On the opposite to C. neoformans and A. fumigatus cells which can be collected from host fluids to significant numbers, C. albicans sampling from the host is more problematic since C. albicans cells in the host are associated to host tissues or embedded in organs. This motivated in vitro transcriptional profile experiments in which $C$. albicans growth conditions can mimic stresses encountered by the fungus within its host (see Table 1 for details of significant studies). Alternatively, other studies have co-cultured $C$. albicans with mammalian cells or tissue cultures to obtain transcript profiles reflecting the adaptation of this fungal pathogen to different host cell types (see Table 1). In these conditions, the recovery and enrichment of $C$. albicans cells is not technically difficult. These data may partially reflect the real gene expression landscape of C. albicans in the host. It is now understood that transcriptional networks can be shaped by different profiles between in vitro and in vivo experiments, thus highlighting the value of conducting such studies directly during infection (Fanning et al., 2012; $\mathrm{Xu}$ et al., 2015). For example, there is only one commonly regulated transcription factor ( $S F U 1$, which is involved in iron homeostasis) between the in vitro and in vivo response to caspofungin, although 18 and 13 transcription factors genes are each upregulated by caspofungin in vivo and in vitro, respectively (Xu et al., 2015). Furthermore, the exploration of transcriptional data from in vivo conditions and their interpretation for biological relevance depends to some extent on the type of applied reference conditions (in most cases logarithmic growth in vitro; Cairns et al., 2010).

Even though it is technically challenging, several transcriptional studies have been performed on mice organs after systemic infection with C. albicans (Andes et al., 2005; Thewes et al., 2007), or mice feces after GI-infection (Rosenbach et al., 2010), as well as on biofilms grown on bloodstream-placed devices (Nett et al., 2009; see Table 2 for details of significant studies). The different attempts to resolve the $C$. albicans transcriptome in vivo have turned out to be a great challenge for researchers since fungal RNA ratios in recovered infected organs were very low as compared to host RNA. Low fungal RNA ratios in transcript profile experiments that use microarray compromise data quality due the low signal/noise ratio. Likewise, when using RNA-seq approaches, the number of fungal reads may be too low for a comprehensive coverage of the fungal ORFome.

Up to now, different strategies were developed to overcome this problem, including isolation of fungal cells prior to RNA extraction (Andes et al., 2005), or specific fungal RNA amplification post-RNA extraction (Thewes et al., 2007; Table 2). Enrichment of cells before RNA extraction exposed them to environmental changes before stopping transcription and RNA degradation, thus potentially modifying the observed transcriptional response (Andes et al., 2005). RNA amplification may be biased by non-linear amplification of fungal RNA because of the presence of large amounts of host RNA (Thewes et al., 2007). Alternative animal models have also been used such as rabbits (Walker et al., 2009) and zebrafish (Chen et al., 2013) in order to recover higher fungal biomass and to be able to perform direct transcript profiling analyses on fungal RNA.

Most of the studies mentioned so far used microarrays to measure C. albicans transcriptional activity, which is a method with relatively low sensitivity in quantifying the absolute expression values and in the detection of low abundance genes (Draghici et al., 2006). With more recent technologies such as RNA-seq, the detection threshold of non-aboundant transcripts has been decreased as compared to microarrays (Seqc/MaqcIII-Consortium, 2014). RNA-seq is based on established highthroughput DNA sequencing technologies that are now mainly implemented in Illumina sequencing instruments that produce high read numbers $\left(10^{6}-10^{7}\right.$ per sample). RNA-seq has been used in several genome-wide C. albicans transcriptional studies in vitro (Bruno et al., 2010; Dhamgaye et al., 2012; Hnisz et al., 2012) or with C. albicans-infected mammalian cells with different resolutions (Table 1; Tierney et al., 2012; Liu et al., 2015). So far, only two studies have attempted the analysis of the $C$. albicans transcriptome by RNA-seq directly from host infections (Bruno et al., 2015; Liu et al., 2015). These reports used either infected human samples or samples from mice systemically infected with C. albicans. However, these studies were confronted with the low fungal transcripts proportion in the total extracted RNA. These samples had limited sequencing depth, thus resulting in the detection of a small number of highly expressed genes only. 
TABLE 1 | Representative in vitro and ex-vivo transcriptomic analysis performed with Candida Albicans.

\begin{tabular}{|c|c|c|c|c|c|}
\hline In vitro condition & Ex vivo condition & Sampling time points & Expression analysis & $\begin{array}{l}\text { Number of } \\
\text { regulated genes }\end{array}$ & Reference \\
\hline Shift to serum at $37^{\circ} \mathrm{C}$ & & $30 \mathrm{~min}, 6 \mathrm{~h}$ & Microarray (6580 ORF) & 742 & Nantel et al., 2002 \\
\hline $\begin{array}{l}\text { Heat stress, osmotic } \\
\text { stress, oxidative stress }\end{array}$ & & $10,30,60 \mathrm{~min}$ & Microarray (6580 ORF) & 972 & Enjalbert et al., 2003 \\
\hline pH shift (pH 4 vs. pH 8) & & $4 \mathrm{~h}$ & Microarray (6175 ORF) & 1084 & Bensen et al., 2004 \\
\hline Biofilm formation & & $24,48,72 \mathrm{~h}$ & Microarray (5907 ORF) & $748-856$ & Garcia-Sanchez et al., 2004 \\
\hline Nitric oxide exposure & & $10,40,70,120 \mathrm{~min}$ & Microarray (6550 ORF) & 131 & Hromatka et al., 2005 \\
\hline $\begin{array}{l}\text { Tetracycline-dependent } \\
\text { UME6 expression }\end{array}$ & & $3,10 \mathrm{~h}$ & Microarray (6346 ORF) & 238 & Carlisle and Kadosh, 2013 \\
\hline Low vs. high iron & & $5 \mathrm{~h}$ & Microarray (6111 ORF) & 521 & Chen and Noble, 2012 \\
\hline \multirow[t]{14}{*}{ Spider medium } & & $8 \mathrm{~h}$ & nanoString (293 ORF) & $N A^{b}$ & Finkel et al., 2012 \\
\hline & Human blood & $10,20,30,60 \mathrm{~min}$ & Membrane arrays (2002 ORF) & 640 & Fradin et al., 2003 \\
\hline & $\begin{array}{l}\text { Human Blood fractions } \\
\text { (PMN, MNC, Plasma) }\end{array}$ & $30 \mathrm{~min}$ & Microarray (6039 ORF) & 1518 & Fradin et al., 2005 \\
\hline & $\begin{array}{l}\text { Human neutrophils, } \\
\text { monocytes }\end{array}$ & $60,80 \mathrm{~min}$ & Microarray (6550 ORF) & 246 & Rubin-Bejerano et al., 2003 \\
\hline & Murine macropahges & $1,6 \mathrm{~h}$ & Microarray (7600 ORF) & 545 & Lorenz et al., 2004 \\
\hline & $\begin{array}{l}\text { Reconstituted human oral } \\
\text { epithelium }\end{array}$ & $1,3,6,12,24 \mathrm{~h}$ & Microarray (6039 ORF) & 164 (upregulated) $^{c}$ & Zakikhany et al., 2007 \\
\hline & $\begin{array}{l}\text { Reconstituted human oral } \\
\text { epithelium }\end{array}$ & $30 \mathrm{~min}$ & Microarray (6320 ORF) & 268 & Spiering et al., 2010 \\
\hline & Perfused pig liver & $12 \mathrm{~h}$ & Microarray (6039 ORF) & 63 & Thewes et al., 2007 \\
\hline & Human oral epithelial cells & $20,60,180 \mathrm{~min}$ & Microarray (6039 ORF) & 607 & Wächtler et al., 2011 \\
\hline & Murine dendritic cells & $30,60,90,120 \mathrm{~min}$ & RNA-seq & 545 & Tierney et al., 2012 \\
\hline & Human epithelial cells & $45,90,180 \mathrm{~min}$ & Microarray (6266 ORF) & $44-242$ & Park et al., 2009 \\
\hline & Human endothelial cells & $45,90,180 \mathrm{~min}$ & Microarray (6266 ORF) & $54-63$ & Park et al., 2009 \\
\hline & Human endothelial cells & $1,5,5,8 \mathrm{~h}$ & RNA-seq & $15-31$ & Liu et al., 2015 \\
\hline & Human epithelial cell & $1,5,5,8 \mathrm{~h}$ & RNA-seq & $21-63$ & Liu et al., 2015 \\
\hline
\end{tabular}

a/nclude genes that are $\geq 2$-fold up- and down-regulated.

${ }^{\mathrm{b}} \mathrm{NA}$, not available.

'Only upregulated genes were available.

TABLE 2 | Representative in vivo transcriptomic analysis performed with C. albicans.

\begin{tabular}{|c|c|c|c|c|c|c|c|}
\hline Host & $\begin{array}{l}\text { Route of } \\
\text { infection }\end{array}$ & Time points & $\begin{array}{l}\text { Organ/tissue/ } \\
\text { device }\end{array}$ & Expression analysis & $\begin{array}{l}\text { Nucleic acids } \\
\text { amplification }\end{array}$ & $\begin{array}{l}\text { Number of } \\
\text { regulated genes }^{a}\end{array}$ & Reference \\
\hline Human & $N A^{b}$ & NA & Oral cavity & Microarray (6039 ORF) & No & 189 (upregulated) & Zakikhany et al., 2007 \\
\hline $\begin{array}{l}\text { Neutropenic } \\
\text { mice }\end{array}$ & IV infection ${ }^{c}$ & $6,9,15 \mathrm{~h}$ & Kidneys & Microarray (6737 ORF) & No & 652 & Andes et al., 2005 \\
\hline $\begin{array}{l}\text { Immuno } \\
\text { suppressed } \\
\text { mice }\end{array}$ & OP infection ${ }^{d}$ & 1,5 days & Tongue & nanoString (134 ORF) & No & $\begin{array}{l}65 \text { (vs. Spider } \\
\text { medium) }\end{array}$ & Fanning et al., 2012 \\
\hline Mice & IP infection ${ }^{e}$ & $0.5,3,5 \mathrm{~h}$ & IP space & Microarray (6039 ORF) & Yes & 476 & Thewes et al., 2007 \\
\hline $\begin{array}{l}\text { Antibiotic- } \\
\text { treated } \\
\text { mice }\end{array}$ & Gl infection ${ }^{f}$ & 3 days & Gl tract (cecum) & Microarray (6333 ORF) & No & 440 & Rosenbach et al., 2010 \\
\hline Mice & $\begin{array}{l}\text { Central venous } \\
\text { catheter }\end{array}$ & $12,24 \mathrm{~h}$ & Catheter & Microarray (6737 ORF) & No & $\begin{array}{l}545(12 \mathrm{~h}) \\
1034(24 \mathrm{~h})\end{array}$ & Nett et al., 2009 \\
\hline Rabbit & IV infection & 3 days & Kidneys & Microarrays (6580 ORF) & No & 108 & Walker et al., 2009 \\
\hline Zebra fish & IP infection & $0.5-18 \mathrm{~h}$ & Whole fish & Microarray (6205 ORF) & No & $120(0.5-2$ h) & Chen et al., 2013 \\
\hline Mice & IP infection & $48 \mathrm{~h}$ & IP space & nanoString (145 ORF) & No & NA & Cheng et al., 2013 \\
\hline
\end{tabular}

alnclude genes that are $\geq 2$-fold up- and down-regulated.

bNA, not available.

cIntravenous infection.

dOro-pharyngeal infection.

eIntra-peritoneal infection.

${ }^{f}$ Gastro-intestinal infection. 


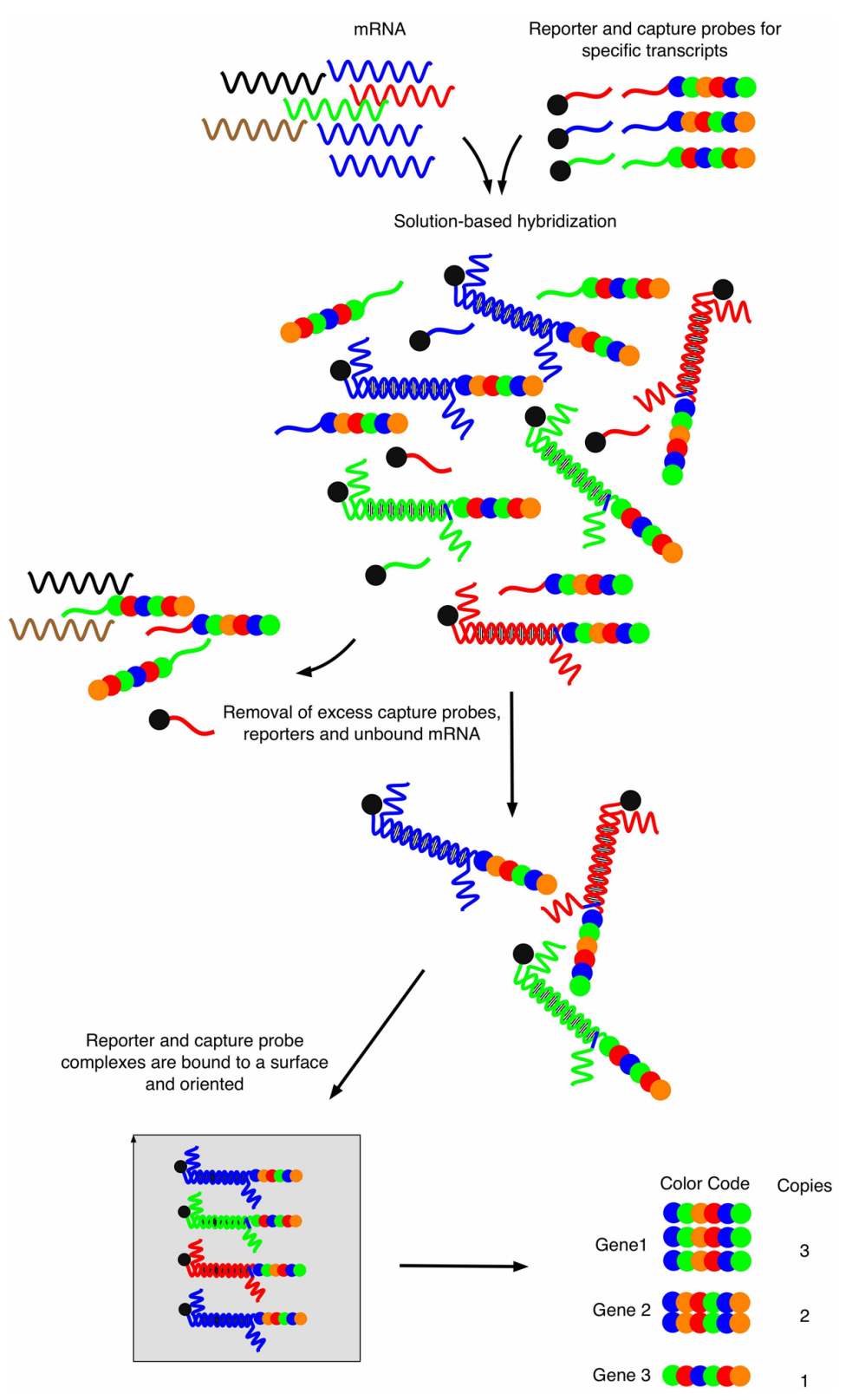

FIGURE 1 | Workflow of the nanoString strategy. Capture probes are bound to biotin and reporter probes consist of four different fluorophores that are arranged at six different positions, thus providing a specific fluorescent signature for each probe. After mRNA hybridization and removal of excess unbound material, hybrid molecules are fixed onto a surface using electrical current which will orient all molecules. Sequential reading with a fluorescent source provides signal signatures for each specific mRNA in a quantitative manner. Adapted from Fortina and Surrey (2008).

\section{NOVEL APPROACHES IN FUNGAL TRANSCRIPTOME PROFILING IN THE HOST}

Novel approaches to enable transcript profiling directly from host samples have emerged recently. The first technology, also called "nanoString" (Geiss et al., 2008), consists upon two key steps (Figure 1). Briefly, two probes are specifically designed for each target gene. One probe, called the capture-probe, is linked to biotin and helps to immobilize the molecules of interest onto a counting stand. The second probe is target-specific and is called the reporter probe. This probe is made of six fluorochromes of four different colors, defining a fluorochrome code specific to each target molecule. This color code confers the technique a very high sensitivity and enables the analysis of quantity-limited biological samples. The mRNAs of selected genes can hybridize to both their corresponding capture-probe and the reporter probes, which are both in excess in the reaction liquid. The main interest of this detection method is that it is direct and does not require linear (array) or exponential (PCR) amplifications. The 
method provides simultaneous digital readouts of the relative abundance of the selected mRNA species within a sample. The restricted number of sample manipulation steps together with the absence of enzymatic reaction (in most cases) allows precise and physiologically correct quantifications from starting material.

The nanoString technology was adapted to C. albicans and allowed the fungal transcription profiling on mice samples containing less than $0,1 \%$ of $C$. albicans RNA (Fanning et al., 2012). Other studies have used the nanoString technology but targeting a restricted number of C. albicans genes (248 out of a total of 6218 ORFs) from host samples originating from systemic and intra-peritoneal candidiasis in animal models (Finkel et al., 2012; Cheng et al., 2013; Xu et al., 2015). The 248 genes comprised environmentally responsive genes chosen from published genome-wide datasets. A second panel of C. albicans gene targets was based on the entire set of C. albicans transcription factors (231; Xu et al., 2015). In addition, Chung et al. (2014) reported the use of nanoString for analysis of A. fumigatus expression from an in vivo murine model of invasive pulmonary aspergillosis. Here the authors used a set of 60 different probes only (Chung et al., 2014). There is no doubt that nanoString is a powerful technology with high multiplexing capability and which overcomes the problem of low fungus/host RNA ratio. Still, this technology is provided by a single supplier, it is limited to a maximal number of target genes (800) and thus cannot yield a comprehensive transcriptional profile (Geiss et al., 2008).

Another technology that enables specific enrichment of a microbial transcriptome in a host is the bait capture method (SureSelect, Agilent), whose principle is outlined in Figure 2. This

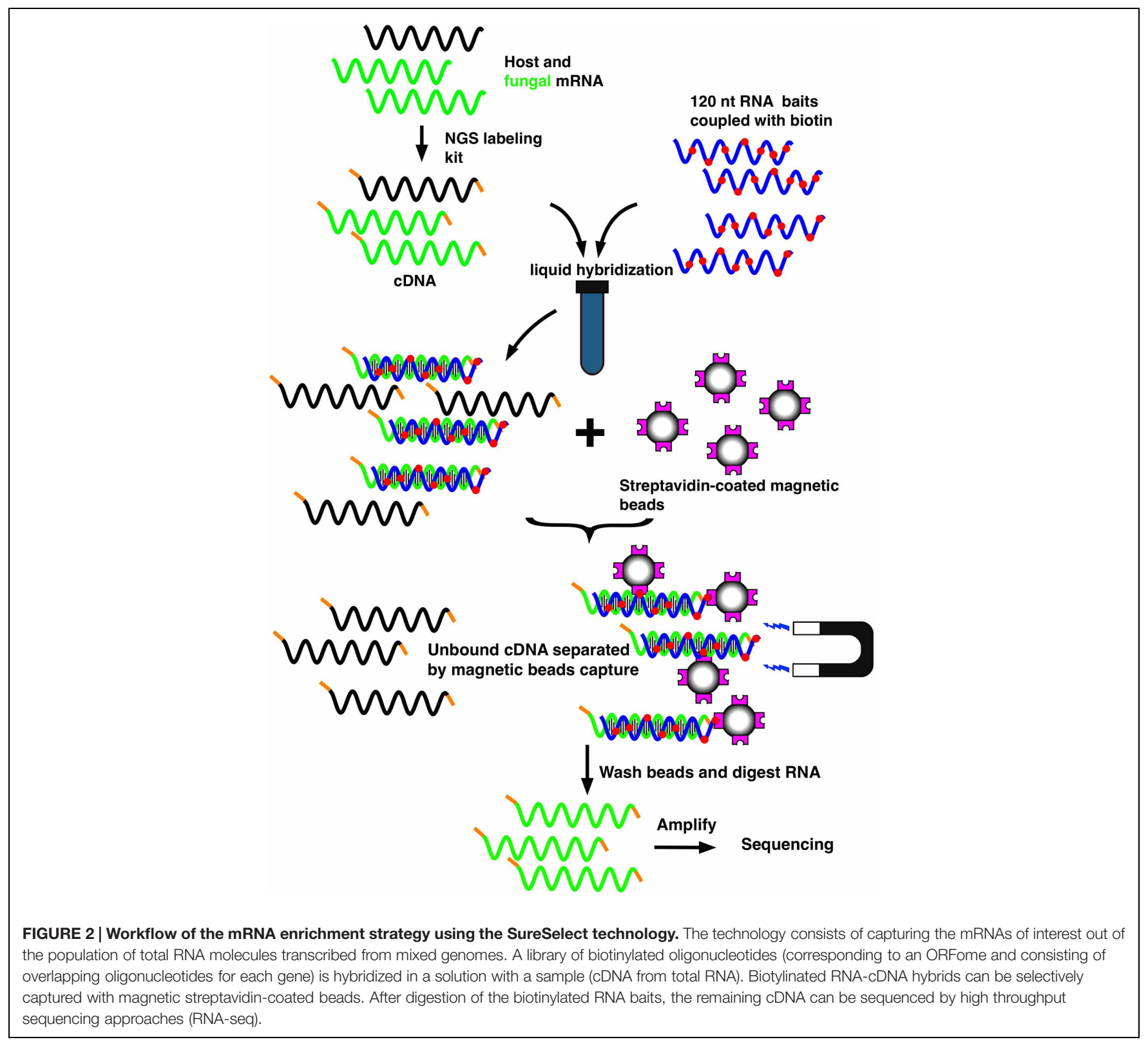




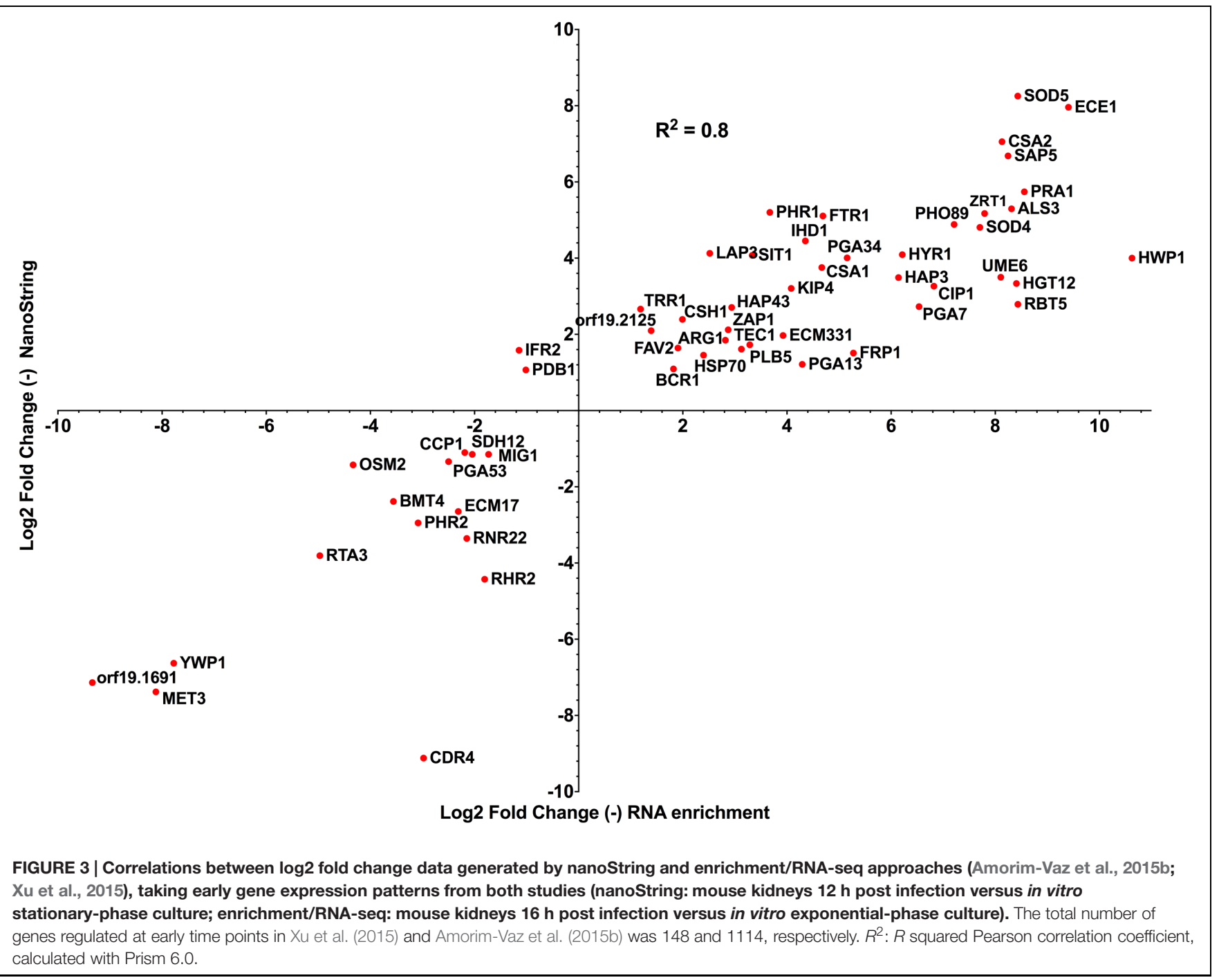

method was originally used to analyze the human exome (Bowne et al., 2011; Diaz-Horta et al., 2012; McDonald et al., 2012; Chilamakuri et al., 2014) and consists of capturing the sequences of interest out of the population of total RNA molecules transcribed from the whole human genome. The hybridization is carried out in a solution containing a library of biotinylated oligonucleotides corresponding to the human exome and the sample (cDNA from total RNA). The biotylinated RNA-cDNA hybrids are next selectively captured using magnetic streptavidin beads. After extensive washing steps, the remaining cDNAs can be released after digestion of the biotinylated RNA baits and are further processed for deep sequencing. We have recently adapted this technology to $C$. albicans, by designing oligonucleotides complementary to the ORFome of this fungus (Amorim-Vaz et al., 2015b). Using an online accessible platform (https:// earray.chem.agilent.com/earray/), the design of biotinylated oligonucleotides can be undertaken and customized. A total of 55,342 bait probes were designed to cover 6,094 C. albicans ORFs. Due to cost limitations, the first 250 nucleotides of each gene were not covered in the bait design, resulting in an average of nine probes for each ORF. The use of this capture system on RNA obtained from infected host tissues resulted in enrichments in the proportion of C. albicans transcripts of more than 500fold and in RNA-seq libraries containing more than $50 \%$ of fungal transcripts. To verify that neither this enrichment nor the predominating background of host material introduced a bias in the results, a simple validation was carried out. RNA from C. albicans was mixed with host RNA (1\% of C. albicans, $99 \%$ of uninfected host). This spiked RNA was next subjected to enrichment with the biotinylated bait system. The results obtained from sequencing these samples were compared to those of sequencing the same $C$. albicans RNA without the presence of host RNA and without enrichment. Using this approach, we were able to verify that there was no bias for $97 \%$ of the genes. Therefore, the relative amount of each gene was the same whether the samples were subjected to the enrichment procedures or not. Moreover, a machine learning approach helped to delimitate the necessary features for the baits in order to efficiently capture their target genes. Such information will be useful for future designs of bait libraries, either targeting C. albicans or other organisms. 
This enrichment method allowed RNA-sequencing of C. albicans from infected mouse kidneys, after 16 and $48 \mathrm{~h}$ of infection, and from infected Galleria mellonella larvae, 2 and $24 \mathrm{~h}$ post-infection. These samples revealed a high resolution transcriptome, showing the expression levels of over $80 \%$ of all C. albicans genes, constituting a huge improvement in resolution relatively to previous in vivo transcriptional analyses of this microorganism. Over 1000 genes were found to be statistically up- or down-regulated in vivo relatively to in vitro when performing a meta-analysis that identified genes commonly regulated in the four different conditions. Several functions were enriched among these genes, including some typically associated with virulence, such as adhesion, iron homeostasis, stress response, response to starvation, and biofilm formation. On the other hand, such detailed landscape of the $C$. albicans gene expression profile allowed the identification of a large number of genes that were so far ignored to participate in the process of host invasion and infection, and these alone will be targets of investigation for years to come.

The two models of infection, mouse and insect larvae, elicited surprisingly similar transcriptional responses from C. albicans, highlighting the adequation of this insect model to study C. albicans virulence. These data are consistent with studies that revealed a good correlation between $C$. albicans virulence in mice invasive models and the insect larvae (Brennan et al., 2002; Amorim-Vaz et al., 2015a). Unfortunately, the libraries enriched for $C$. albicans cannot be used to analyze the host transcriptome without a non-negligible bias. Still, dual RNA-seq of host and pathogen can be performed on the same RNA sample, if both a non-enriched and an enriched library are prepared and sequenced.

Taking datasets produced from both technologies analyzing C. albicans systemic infection in mice, we compared sets of C. albicans genes that were common between both studies and estimated the expression levels as compared to in vitro grown cells. We considered only early infection times of both studies for the comparison and only genes that were significantly regulated as compared to in vitro conditions. With a set of 56 genes in common between both studies, the data showed a high correlation $\left(R^{2}: 0.8\right)$ between observed gene expression levels (Figure 3). This high correlation in gene expression profile is remarkable, given the different experimental conditions between both studies (choice of time points, choice of mice strain) and the different analytical approaches taken. Among the genes that were commonly upregulated in both data sets, genes relevant for C. albicans pathogenesis can be identified including: (i) HWP1 (hyphal specific protein involved in adhesion to epithelial cells) and ALS3 (adhesin involved in the adherence of $C$. albicans to endo- and epithelial cells), (ii) ZRT1 and PRA1 (zinc transporter and zinc binding protein important for zinc acquisition of

\section{REFERENCES}

Amorim-Vaz, S., Delarze, E., Ischer, F., Sanglard, D., and Coste, A. T. (2015a). Examining the virulence of Candida albicans transcription factor mutants using
C. albicans) and (iii) FTR1 (a high-affinity iron permease) and SIT1 (a transporter of ferrichrome siderophores). These results suggest that the enrichment/RNA-seq method can be an alternative to nanoString when whole genome data are required.

\section{CONCLUSION AND PERSPECTIVES}

The two novel transcriptional approaches, nanoString and RNAseq following enrichment, represent powerful tools to analyze the behavior of pathogens during infection. With RNA samples directly taken from within its host, the technical challenges of quantification of fungal mRNA in a complex host mixture have now been overcome, with the difference that nanoString targets still a limited number of genes of interest while enrichment/RNAseq is genome-wide. Future applications of enrichment/RNAseq may include the transcriptome analysis of $C$. albicans mutants with reduced virulence. So far, this task was even more challenging than for wild-type strains due to the reduced fungal burdens often found for such mutants in host organs, thus further reducing the proportion of fungal versus host biomass. With the potential of these transcriptome technologies, it will be also possible to investigate $C$. albicans gene expression in other contexts, such as from different organs during systemic infection or during other types of infections, like oropharyngeal candidiasis, mucosal infections or gastrointestinal colonization. Importantly, since these methods allow the selective sequencing of fungal transcripts, it will be now possible to perform such studies directly on human biopsies from solid tissues, even if containing low amounts of fungal cells. Such data will be useful to estimate to which extent the C. albicans transcriptome from clinical samples differs from animal models. Moreover, the possible applications of transcriptome technologies are obviously not limited to $C$. albicans. To apply them to other pathogens, one needs simply to design a set of probes matching the ORFome of the organism of interest. Both approaches currently implicate significant costs given their technical specificities and the need to perform experiments in duplicates or triplicates (for example about 600 USD per sample for analysis of 500 genes by nanoString; about 500 USD for SureSelect application and RNAseq per sample for whole $C$. albicans genome). The significant costs of these technologies are originating from capture probe biosynthesis, which might be reduced in the future by novel chemistry. On the other hand, the expansion of their future use will probably contribute to decrease their price.

\section{ACKNOWLEDGMENT}

This work was supported by Swiss National Science Foundation grant CRSII3_141848 (Sinergia) to DS.

Galleria mellonella and mouse infection models. Front. Microbiol. 6:367. doi: 10.3389/fmicb.2015.00367

Amorim-Vaz, S., Tran, V. D. T., Pradervand, S., Pagni, M., Coste, A. T., and Sanglard, D. (2015b). RNA enrichment method for quantitative transcriptional 
analysis of pathogens in vivo applied to the fungus Candida albicans. mBio 6:e942-e955. doi: 10.1128/mBio.00942-15

Andes, D., Lepak, A., Pitula, A., Marchillo, K., and Clark, J. (2005). A simple approach for estimating gene expression in Candida albicans directly from a systemic infection site. J. Infect. Dis. 192, 893-900. doi: 10.1086/432104

Bensen, E., Martin, S., Li, M., Berman, J., and Davis, D. (2004). Transcriptional profiling in Candida albicans reveals new adaptive responses to extracellular $\mathrm{pH}$ and functions for Rim101p. Mol. Microbiol. 54, 1335-1351. doi: 10.1111/j.13652958.2004.04350.x

Bertuzzi, M., Schrettl, M., Alcazar-Fuoli, L., Cairns, T. C., Muñoz, A., Walker, L. A., et al. (2014). The pH-responsive PacC transcription factor of Aspergillus fumigatus governs epithelial entry and tissue invasion during pulmonary aspergillosis. PLoS Pathog 10:e1004413. doi: 10.1371/journal.ppat.1004413

Bowne, S. J., Humphries, M. M., Sullivan, L. S., Kenna, P. F., Tam, L. C., Kiang, A. S., et al. (2011). A dominant mutation in RPE65 identified by whole-exome sequencing causes retinitis pigmentosa with choroidal involvement. Eur. J. Hum. Genet. 19, 1074-1081. doi: 10.1038/ejhg.2011.86

Brennan, M., Thomas, D. Y., Whiteway, M., and Kavanagh, K. (2002). Correlation between virulence of Candida albicans mutants in mice and Galleria mellonella larvae. FEMS Immunol. Med. Microbiol. 34, 153-157. doi: 10.1111/j.1574695X.2002.tb00617.x

Brown, G. D., Denning, D. W., Gow, N. A., Levitz, S. M., Netea, M. G., and White, T. C. (2012). Hidden killers: human fungal infections. Sci. Transl. Med. 4:165rv113. doi: 10.1126/scitranslmed.3004404

Bruno, V. M., Shetty, A. C., Yano, J., Fidel, P. L., Noverr, M. C., and Peters, B. M. (2015). Transcriptomic analysis of vulvovaginal candidiasis identifies a role for the NLRP3 inflammasome. mBio 6:e182-e115. doi: 10.1128/mBio.00182-15

Bruno, V. M., Wang, Z., Marjani, S. L., Euskirchen, G. M., Martin, J., Sherlock, G., et al. (2010). Comprehensive annotation of the transcriptome of the human fungal pathogen Candida albicans using RNA-seq. Genome Res. 20, 1451-1458. doi: $10.1101 /$ gr.109553.110

Cairns, T., Minuzzi, F., and Bignell, E. (2010). The host-infecting fungal transcriptome. FEMS Microbiol. Lett. 307, 1-11. doi: 10.1111/j.1574-6968.2010.01961.x

Carlisle, P. L., and Kadosh, D. (2013). A genome-wide transcriptional analysis of morphology determination in Candida albicans. Mol. Biol. Cell 24, 246-260. doi: 10.1091/mbc.E12-01-0065

Chen, C., and Noble, S. M. (2012). Post-transcriptional regulation of the SEF1 transcription factor controls the virulence of Candida albicans in its mammalian host. PLoS Pathog 8:e1002956. doi: 10.1371/journal.ppat.1 002956

Chen, Y., Toffaletti, D. L., Tenor, J. L., Litvintseva, A. P., Fang, C., Mitchell, T. G., et al. (2014). The Cryptococcus neoformans transcriptome at the site of human meningitis. $m$ Bio 5, e1087-e1093. doi: 10.1128/mBio.01087-13

Chen, Y. Y., Chao, C. C., Liu, F. C., Hsu, P. C., Chen, H. F., Peng, S. C., et al. (2013). Dynamic transcript profiling of Candida albicans infection in zebrafish: a pathogen-host interaction study. PLOS ONE 8:e72483. doi: 10.1371/journal.pone.0072483

Cheng, S., Clancy, C. J., Xu, W., Schneider, F., Hao, B., Mitchell, A. P., et al. (2013). Profiling of Candida albicans gene expression during intra-abdominal candidiasis identifies biologic processes involved in pathogenesis. J. Infect. Dis. 208, 1529-1537. doi: 10.1093/infdis/jit335

Chilamakuri, C. S., Lorenz, S., Madoui, M. A., Vodak, D., Sun, J., Hovig, E., et al. (2014). Performance comparison of four exome capture systems for deep sequencing. BMC Genomics 15:449. doi: 10.1186/1471-2164-15-449

Chung, D., Barker, B. M., Carey, C. C., Merriman, B., Werner, E. R., Lechner, B. E., et al. (2014). ChIP-seq and in vivo transcriptome analyses of the Aspergillus fumigatus SREBP SrbA reveals a new regulator of the fungal hypoxia response and virulence. PLoS Pathog 10:e1004487. doi: 10.1371/journal.ppat.10 04487

Dhamgaye, S., Bernard, M., Lelandais, G., Sismeiro, O., Lemoine, S., Coppée, J.-Y., et al. (2012). RNA sequencing revealed novel actors of the acquisition of drug resistance in Candida albicans. BMC Genomics 13:396. doi: 10.1186/1471-216413-396

Diaz-Horta, O., Duman, D., Foster, J. II, Sirmaci, A., Gonzalez, M., Mahdieh, N., et al. (2012). Whole-exome sequencing efficiently detects rare mutations in autosomal recessive nonsyndromic hearing loss. PLoS ONE 7:e50628. doi: 10.1371/journal.pone.0050628
Draghici, S., Khatri, P., Eklund, A. C., and Szallasi, Z. (2006). Reliability and reproducibility issues in DNA microarray measurements. Trends Genet. 22, 101-109. doi: 10.1016/j.tig.2005.12.005

Enjalbert, B., Nantel, A., and Whiteway, M. (2003). Stress-induced gene expression in Candida albicans: absence of a general stress response. Mol. Biol. Cell 14, 1460-1467. doi: 10.1091/mbc.E02-08-0546

Fanning, S., Xu, W., Solis, N., Woolford, C. A., Filler, S. G., and Mitchell, A. P. (2012). Divergent targets of Candida albicans biofilm regulator Bcrl in vitro and in vivo. Eukaryot. Cell 11, 896-904. doi: 10.1128/EC.00103-12

Finkel, J. S., Xu, W., Huang, D., Hill, E. M., Desai, J. V., Woolford, C. A., et al. (2012). Portrait of Candida albicans adherence regulators. PLoS Pathog 8:e1002525. doi: 10.1371/journal.ppat.1002525

Fortina, P., and Surrey, S. (2008). Digital mRNA profiling. Nat. Biotechnol. 26, 293-294. doi: 10.1038/nbt0308-293

Fradin, C., De Groot, P., Maccallum, D., Schaller, M., Klis, F., Odds, F. C., et al. (2005). Granulocytes govern the transcriptional response, morphology and proliferation of Candida albicans in human blood. Mol. Microbiol. 56, 397-415. doi: 10.1111/j.1365-2958.2005.04557.x

Fradin, C., Kretschmar, M., Nichterlein, T., Gaillardin, C., D'enfert, C., and Hube, B. (2003). Stage-specific gene expression of Candida albicans in human blood. Mol. Microbiol. 47, 1523-1543. doi: 10.1046/j.1365-2958.2003.03396.x

Garcia-Sanchez, S., Aubert, S., Iraqui, I., Janbon, G., Ghigo, J., and D'enfert, C. (2004). Candida albicans biofilms: a developmental state associated with specific and stable gene expression patterns. Eukaryot. Cell 3, 536-545. doi: 10.1128/EC.3.2.536-545.2004

Geiss, G. K., Bumgarner, R. E., Birditt, B., Dahl, T., Dowidar, N., Dunaway, D. L., et al. (2008). Direct multiplexed measurement of gene expression with color-coded probe pairs. Nat. Biotechnol. 26, 317-325. doi: 10.1038/nbt1385

Hnisz, D., Bardet, A. F., Nobile, C. J., Petryshyn, A., Glaser, W., Schöck, U., et al. (2012). A histone deacetylase adjusts transcription kinetics at coding sequences during Candida albicans morphogenesis. PLoS Genetics 8:e1003118. doi: 10.1371/journal.pgen.1003118.g006

Hromatka, B. S., Noble, S. M., and Johnson, A. D. (2005). Transcriptional response of Candida albicans to nitric oxide and the role of the YHB1 gene in nitrosative stress and virulence. Mol. Biol. Cell 16, 4814-4826. doi: 10.1091/mbc.E0505-0435

Liu, Y., Shetty, A. C., Schwartz, J. A., Bradford, L. L., Xu, W., Phan, Q. T., et al. (2015). New signaling pathways govern the host response to C. albicans infection in various niches. Genome Res. 25, 679-689. doi: 10.1101/gr.187427.114

Lorenz, M. C., Bender, J. A., and Fink, G. R. (2004). Transcriptional response of Candida albicans upon internalization by macrophages. Eukaryot. Cell 3, 1076-1087. doi: 10.1128/EC.3.5.1076-1087.2004

McDonagh, A., Fedorova, N. D., Crabtree, J., Yu, Y., Kim, S., Chen, D., et al. (2008). Sub-telomere directed gene expression during initiation of invasive aspergillosis. PLoS Pathog. 4:e1000154. doi: 10.1371/journal.ppat.1000154

McDonald, K. K., Stajich, J., Blach, C., Ashley-Koch, A. E., and Hauser, M. A. (2012). Exome analysis of two limb-girdle muscular dystrophy families: mutations identified and challenges encountered. PLOS ONE 7:e48864. doi: 10.1371/journal.pone.0048864

Nantel, A., Dignard, D., Bachewich, C., Harcus, D., Marcil, A., Bouin, A.-P., et al. (2002). Transcription profiling of Candida albicans cells undergoing the yeast-to-hyphal transition. Mol. Biol. Cell 13, 3452-3465. doi: 10.1091/mbc.E0205-0272

Nett, J. E., Lepak, A. J., Marchillo, K., and Andes, D. R. (2009). Time course global gene expression analysis of an in vivo Candida biofilm. J. Infect. Dis. 200, 307-313. doi: 10.1086/599838

Odds, F. C. (1988). The Ecology of Candida and Epidemiology of Candidosis. Candida and Candidosis: a Review and Bibliography. London: Balliere Tindall.

Park, H., Liu, Y., Solis, N., Spotkov, J., Hamaker, J., Blankenship, J. R., et al. (2009). Transcriptional responses of Candida albicans to epithelial and endothelial cells. Eukaryot. Cell 8, 1498-1510. doi: 10.1128/EC.00165-09

Pfaller, M. A., and Diekema, D. J. (2010). Epidemiology of invasive mycoses in North America. Crit. Rev. Microbiol. 36, 1-53. doi: 10.3109/104084109032 41444

Rosenbach, A., Dignard, D., Pierce, J. V., Whiteway, M., and Kumamoto, C. A. (2010). Adaptations of Candida albicans for growth in the mammalian intestinal tract. Eukaryot. Cell 9, 1075-1086. doi: 10.1128/EC.00034-10 
Rubin-Bejerano, I., Fraser, I., Grisafi, P., and Fink, G. (2003). Phagocytosis by neutrophils induces an amino acid deprivation response in Saccharomyces cerevisiae and Candida albicans. Proc. Natl. Acad. Sci. U.S.A. 100, 11007-11012. doi: 10.1073/pnas.18344 81100

Seqc/Maqc-III-Consortium (2014). A comprehensive assessment of RNAseq accuracy, reproducibility and information content by the Sequencing Quality Control Consortium. Nat. Biotechnol. 32, 903-914. doi: 10.1038/ nbt.2957

Spiering, M. J., Moran, G. P., Chauvel, M., Maccallum, D. M., Higgins, J., Hokamp, K., et al. (2010). Comparative transcript profiling of Candida albicans and Candida dubliniensis identifies SFL2, a C. albicans gene required for virulence in a reconstituted epithelial infection model. Eukaryot Cell 9, 251-265. doi: 10.1128/EC.00291-09

Thewes, S., Kretschmar, M., Park, H., Schaller, M., Filler, S. G., and Hube, B. (2007). In vivo and ex vivo comparative transcriptional profiling of invasive and non-invasive Candida albicans isolates identifies genes associated with tissue invasion. Mol. Microbiol. 63, 1606-1628. doi: 10.1111/j.1365-2958.2007. 05614.x

Tierney, L., Linde, J., Müller, S., Brunke, S., Molina, J. C., Hube, B., et al. (2012). An interspecies regulatory network inferred from simultaneous RNA-seq of Candida albicans invading innate immune cells. Front. Microbiol. 3:85. doi: 10.3389/fmicb.2012.00085

Wächtler, B., Wilson, D., Haedicke, K., Dalle, F., and Hube, B. (2011). From attachment to damage: defined genes of Candida albicans mediate adhesion, invasion and damage during interaction with oral epithelial cells. PLoS ONE 6:e17046. doi: 10.1371/journal.pone.0017046

Walker, L. A., Maccallum, D. M., Bertram, G., Gow, N. A. R., Odds, F. C., and Brown, A. J. P. (2009). Genome-wide analysis of Candida albicans gene expression patterns during infection of the mammalian kidney. Fungal Genet. Biol. 46, 210-219. doi: 10.1016/j.fgb.2008.10.012

Xu, W., Solis, N. V., Ehrlich, R. L., Woolford, C. A., Filler, S. G., and Mitchell, A. P. (2015). Activation and alliance of regulatory pathways in C. albicans during mammalian infection. PLoS Biol. 13:e1002076. doi: 10.1371/journal.pbio.1002076

Zakikhany, K., Naglik, J. R., Schmidt-Westhausen, A., Holland, G., Schaller, M., and Hube, B. (2007). In vivo transcript profiling of Candida albicans identifies a gene essential for interepithelial dissemination. Cell Microbiol. 9, 2938-2954. doi: 10.1111/j.1462-5822.2007.01009.x

Conflict of Interest Statement: The authors declare that the research was conducted in the absence of any commercial or financial relationships that could be construed as a potential conflict of interest.

Copyright (c) 2016 Amorim-Vaz and Sanglard. This is an open-access article distributed under the terms of the Creative Commons Attribution License (CC BY). The use, distribution or reproduction in other forums is permitted, provided the original author(s) or licensor are credited and that the original publication in this journal is cited, in accordance with accepted academic practice. No use, distribution or reproduction is permitted which does not comply with these terms. 